\title{
A participação social mediada pelas tecnologias de informação e comunicação - TIC
}

\section{Daniel Roedel}

Administrador, doutorando do Programa de Políticas Públicas e Formação Humana da Úniversidade do Estado do Rio de Janeiro, MSc em Bens Culturais e Projetos Sociais pela FGV-RJ (2009). Possui livros em coautoria sobre estratégia, gestão e sustentabilidade.

\section{Resumo}

O artigo aborda o uso das tecnologias de informação e comunicação pelos movimentos sociais, destacando seu potencial de mobilização, bem como restrições. Alerta que as TIC não são neutras, pois reproduzem os conflitos do ambiente concreto e cumprem papel político no atual contexto. Apresenta - Marco Civil da Internet, em implementação no Brasil, como importante instrumento de apoio à participação social, enfatizando, porém, que a disputa pelo uso democrático da rede está aberta e dependerá da correlação de forças na sociedade civil.

Palavras-chave: Participação; Tecnologias de informação e comunicação; Internet

\section{Abstract}

The article discusses the use of information and communication technologies by social movements, highlighting both their potential for mobilization and restrictions. Warns that ICTs are not neutral once reproduce the concrete environment conflicts and plays a political role in the current context. It displays the recent Law of the internet, being implemented in Brazil as an important tool to support social participation by emphasizing, however, that the struggle for democratic net usage is open and will depend on the correlation of forces in civil society.

Keywords: Participation; Information and communications technology; Internet

\section{Resumen}

El artículo aborda el uso de las tecnologías de información y comunicación por los movimientos sociales, destacando su potencial de movilización y restricciones. Advierte que las TIC no son neutrales porque reproducen los conflictos del entorno concreto y tienen un papel político en el contexto actual. Muestra la nueva ley de Internet en Brasil como una herramienta importante para apoyar la participación social, haciendo hincapié, sin embargo, que la lucha por el uso democrático de la red sigue abierta y dependerá de la correlación de fuerzas en la sociedad civil.

Palabras clave: Participación; Tecnología de la información y la comunicación; Internet 


\section{Introdução}

A expansão e sofisticação das tecnologias de informação e comunicação (TIC) se por um lado deram um amplo suporte ao processo de globalização de mercados, por outro também causaram profundos impactos nas pessoas e na sociedade em geral. Sua utilização não só propiciou a circulação de capitais pelo planeta e a ampliação da terceirização da produção, como também disseminou o modo de vida e a cultura dos países hegemônicos, especialmente os Estados Unidos, na sociedade capitalista. Um modo de vida que tende a subsumir outras culturas e universalizar um tipo de sociedade pautada pelo consumo intenso e imediato. Tenta exercer fascínio e sedução, ao mesmo tempo em que oculta e naturaliza as consequências sociais e ambientais adversas.

Trata-se, portanto, de um papel político e ideológico que ao consagrar a sociedade orientada para o mercado transmite a ideia de um determinismo tecnológico como se o próprio desenvolvimento das tecnologias possuísse autonomia e vontade próprias e se organizasse fora do contexto social.

No entanto, as tecnologias não são neutras nem autônomas em relação à realidade social. Pelo contrário, são produtos dessa realidade e a reproduzem com suas relações de poder e interesses dominantes ou até mesmo hegemônicos. Uma relação que é histórica e não está restrita ao desenvolvimento e aplicação das TIC. Já no século XIX Karl Marx (1971) evidenciou essa relação ao identificar o uso da maquinaria para o aumento da produtividade no trabalho e da exploração do trabalhador.

$\mathrm{Na}$ primeira metade do século XX, as pesquisas desenvolvidas no Instituto para Pesquisa Social da Alemanha, conhecido como Escola de Frankfurt, como por exemplo, os trabalhos de Theodor Adorno e Herbert Marcuse, entre outros relacionaram a tecnologia e a técnica com as relações dominantes. Posteriormente, Andrew Feenberg também desenvolveu estudos críticos sobre a relação entre tecnologia e dominação.

Assim, a tecnologia, bem como a ciência estão intimamente associadas ao desenvolvimento da sociedade industrial capitalista. Elas são socialmente determinadas, isto é, se desenvolvem conforme a orientação dominante na sociedade. Reproduzem as relações sociais e estão submetidas a influências históricas, políticas e culturais (FEENBERG apud DAGNINO e NOVAES, 2004). Desse modo, não podem ser consideradas neutras ou autônomas com relação à vida social, mas um produto das relações de poder que se estabelecem na sociedade e que atua a serviço desse poder.

Mesmo sob uma aparência de neutralidade e de inevitabilidade, as opções tecnológicas na sociedade são decorrentes de escolhas e refletem a disputa política nas lutas sociais, sendo projetadas pelo modo de vida hegemônico. Há uma conexão entre a tecnologia adotada e o que se dissemina como modo de vida ideal. A tecnologia atua assim como um instrumento para estruturar estilos de vida, conforme interesses específicos. Portanto, desempenha um papel político na sociedade a despeito da tentativa de ser apresentada como algo meramente instrumental (Feenberg in NEDER, 2010).

Mas questionar o papel desempenhado pela tecnologia não significa rejeitar o seu uso. Pelo contrário, representa uma tentativa de desmistificação de sua autonomia e neutralidade, bem como a necessidade de se colocar no debate político a sua constituição, finalidade e modos de aplicação.

Adicionalmente, o debate acerca da neutralidade, autonomia ou subordinação da tecnologia é relevante no atual contexto de ampliação da oferta de novas tecnologias 
de informação e comunicação na sociedade. Sua ampla disseminação se dá para além das práticas globais de comércio, indústria e finanças. São adotadas como meio de sociabilidade, para o exercício de cidadania e por movimentos sociais contestatórios à globalização atual. Do mesmo modo, governos utilizam as TIC, com ênfase na internet, para aumentar a legitimidade da gestão pública se aproximando de modo virtual da sociedade civil.

\section{Internet e mercado}

A internet surgiu no contexto da Guerra Fria nos anos 1960 como instrumento militar nos Estados Unidos e teve sua utilização disseminada na sociedade em geral a partir dos anos 1990. Com seus recursos comunicacionais, é percebida como meio de participação, ativismo político e social, e de construção coletiva de conhecimentos (CASTELLS, 2000, 2004, 2008 e 2013; MORAES, 2001).

Castells (2000) destaca que essa ampla difusão das novas tecnologias da informação convergiu para um novo paradigma baseado na microeletrônica, nos computadores e nas telecomunicações. Seu desenvolvimento exerceu um papel fundamental na reestruturação econômica das principais empresas e governos dos países do G-7 na década de 1980. As novas redes de telecomunicação e os sistemas de informação cumpriram papel fundamental na integração global dos mercados financeiros e na fragmentação articulada da produção e do comércio mundiais.

Moraes (2001) cita o ambiente interativo da internet como um componente criativo nas lutas sociais, no qual “organizações não governamentais, associações profissionais, sindicatos e núcleos ativistas, (...), descobrem no ciberespaço possibilidades de difundir suas reivindicações. (...). O que se busca é promover a disseminação de ideias e o máximo de intercâmbios" (MORAES, 2001, p. 125).

Defensores da internet como meio de ativismo social virtual argumentam ainda que as ferramentas da internet possibilitam a mobilização e politização da sociedade civil para diversas causas que tanto podem possuir alcance local, regional, nacional ou global. Moraes (2001) reforça que o espaço da internet é uma "arena complementar de mobilização e politização, somando-se a assembleias, passeatas, atos públicos e panfletos" (MORAES, 2001, p. 128).

Trata-se de um "ciberativismo [que] alicerça campanhas e aspirações à distância, no compasso de causas que se globalizam (...). [É um] canal público de comunicação, livre de regulamentações e controles externos, para disseminar informações e análises que contribuam para o fortalecimento da cidadania e para o questionamento de hegemonias constituídas" (MORAES, 2001, p. 141).

No processo de globalização, a informacionalização e formação de redes, ao mesmo tempo em que contribuem para a produção econômica priva as sociedades de direitos e privilégios, fragmentando identidades e culturas. E no seu bojo, se articulam projetos de resistência e de construção de modos alternativos de poder, que buscam romper com essa relação de dominação. O Movimento Zapatista no México, nos anos 1990, possibilitou, pelas redes virtuais, uma ampla divulgação da causa, sensibilizando a sociedade civil e obrigando o governo mexicano a uma negociação histórica com o movimento social (CASTELLS, 2008; 2004).

Mais recentemente, mobilizações sociais tais como, a Primavera Árabe, os Indignados da Espanha e o Occupy Wall Street, utilizaram amplamente o espaço da internet 
e seus aplicativos, tais como o Twitter e o Facebook na mobilização e comunicação da resistência, difundindo seus princípios e estabelecendo uma comunicação efetiva com a mídia mundial e, em alguns casos, conseguindo êxito em neutralizar iniciativas oficiais que tentavam desqualificar os movimentos e justificar a repressão ${ }^{1}$.

Por outro lado, seguindo a lógica da sociedade gerida pelo capital, rapidamente a internet se tornou uma mercadoria, um objeto de consumo, cujas características se apresentaram muito além de uma ferramenta de comunicação virtual. $\mathrm{O}$ seu potencial de comunicação em rede mundial possibilitou a difusão da ideia de que a realidade virtual estaria suplantando a realidade concreta, transformando-a e criando uma nova sociedade baseada na cooperação, uma cibercultura deslocada do mundo real. Temas como liberdade, autonomia, território livre despido de hierarquias e censura, realidade virtual, assumiram o protagonismo desse novo modo de comunicar, interagir, negociar, aprender. Empresas especializadas em internet (denominadas empresas pontocom) ganharam espaço no mundo dos negócios. Suas ações alcançaram patamares superiores às empresas que atuavam no mundo concreto.

Mas a internet é uma extensão da vida tal como é, em todas as suas dimensões e modalidades. Virtual e real são faces de um mesmo ambiente. E o desenvolvimento da rede no século XXI veio mostrar que é uma liberdade vigiada pelos sistemas de monitoramento e controle e a utilização da rede como negócio coloca filtros que buscam direcionar os usuários para interesses particulares, reproduzindo no ambiente virtual conflitos contradições e interesses do ambiente concreto, prática admitida por Moraes (2001).

A realidade virtual não é uma criação das TIC. Está com o ser humano desde que ele "tomou consciência de si, percebeu que pensava e que o lugar desse ato era, no sentido forte, um não lugar, um espaço que, muito mais tarde, passou a ser chamado de virtual" (RÜDIGER, 2002, p. 89).

O ciberespaço é, pois, a materialização dessa consciência apoiada pelas tecnologias de informação (Idem). No ambiente virtual não há uma nova realidade descolada da realidade concreta. Os padrões de sociabilidade presentes na realidade social se projetam no ambiente virtual. Assim, "a internet tende a reproduzir as contradições do mundo real, embora não todas, além de conferir-lhes novas qualidades; facilita sem dúvida a participação, mas seu tipo tende a ser,sobretudo, o da participação irresponsável” (Idem, p. 122). É o real determinando o virtual e não o seu oposto, embora este virtual possua uma interação com o mundo real.

Ademais, ao se tornar mais um produto ofertado no mercado, a internet está sujeita às regras e disputas desse tipo de organização da vida econômica e social. Longe de ser um espaço autônomo, território livre e democrático de comunicação e participação, ela reproduz os conflitos, as contradições e as batalhas travadas no ambiente concreto.

Cabem, portanto, algumas indagações acerca da relação entre mundo virtual e mundo real. Se concordarmos que nas décadas recentes o mundo social se estendeu para o virtual e o online, como esses mundos estão organizados? São de fato, mundos novos, livres e abertos para a produção, circulação e inovação do conhecimento, ou obedecem às mesmas regras do mundo off-line? Que espaço de autonomia crítica e de inovação pode-se esperar do mundo virtual, se subordinado às regras de acumulação e reprodução do capital, produz e reproduz a ideologia dominante que oferece "mais do mesmo", limitando o espaço para o confronto com o pensamento hegemônico 
e reduzindo a disputa política a mero enfoque instrumental? Tais questões podem contribuir para o entendimento acerca do potencial da internet no ativismo político.

\section{Internet e os limites da participação}

Se considerarmos que a sociabilidade centrada no indivíduo em detrimento de uma vontade coletiva, e a mercantilização do que é socialmente produzido são exemplos da sociedade baseada no capital, e que a realidade concreta se projeta no ambiente virtual, este ambiente reproduz as contradições, limites e restrições desta realidade concreta. Assim, o cerceamento da participação política, a criminalização dos movimentos sociais, o monitoramento do cidadão em nome da segurança do Estado e a despolitização da sociedade estão presentes também no ambiente virtual.

Ao acessar a rede, as informações estão registradas e armazenadas em algum local. O tráfego pode ser monitorado, rastreado e o usuário acompanhado em seus movimentos virtuais e posicionamentos. Tudo pode ser oportunamente utilizado conforme os interesses políticos de governos e empresas. O usuário não possui informações sobre como a sua utilização da rede está sendo conduzida. No ambiente virtual a liberdade pode ser aparente ou restrita, do mesmo modo que na realidade concreta.

Google e Facebook, importantes empresas de internet possuem mais informações sobre os usuários do que estes possuem sobre si mesmos. Com essas informações podem entender como as pessoas se comportam e orientar negócios de empresas sem que o usuário saiba. Podem ainda vigiar a pessoas passo-a-passo e fornecer as informações para as áreas de segurança de governos, como já ocorre atualmente. Ou seja, não há privacidade. Todos podem ser monitorados o tempo todo pelas redes virtuais da internet. Tudo isso de modo mais sofisticado e sutil do que conseguiu imaginar George Orwell ${ }^{2}$.

No caso do Brasil e da América Latina, a possibilidade se torna mais grave devido ao fato de que os caminhos da internet passam pelos Estados Unidos. Assim, o processo de vigilância não se restringe aos cidadãos, mas os próprios governos e empresas podem ser monitorados. Não há garantia de privacidade nem obstáculo imposto por leis. Trata-se de questão política, de geopolítica (ASSANGE et al, 2013).

Governos que buscam expandir as práticas democráticas utilizando a internet para uma aproximação com a sociedade civil; movimentos sociais que buscam mobilizar e comunicar suas ações políticas pela rede; e cidadãos que utilizam a internet para simples lazer, estudos ou ativismo político estão sob vigilância contínua. É o que Assange (idem) denomina de militarização da internet.

A utilização da internet como instrumento de monitoramento e controle dos cidadãos não ocorre apenas por meio de agências governamentais de inteligência. As próprias organizações comerciais cumprem esse papel em articulação com governos. É o caso do Google, que para Silveira (apud ASSANGE, 2015, p. 11), "se tornou uma corporação que integra o sistema de controle, vigilância e expansão do poder do Estado norte-americano".

A militarização da internet é facilitada pelo baixo custo de armazenamento de informações digitalizadas. No caso dos Estados Unidos são copiados e armazenados todos os dados do tráfego da internet no país. Não há necessidade de se suspeitar do usuário nem de haver processo judicial. A lógica da segurança que prevalece é a de coletar primeiro e investigar depois, se for o caso. 


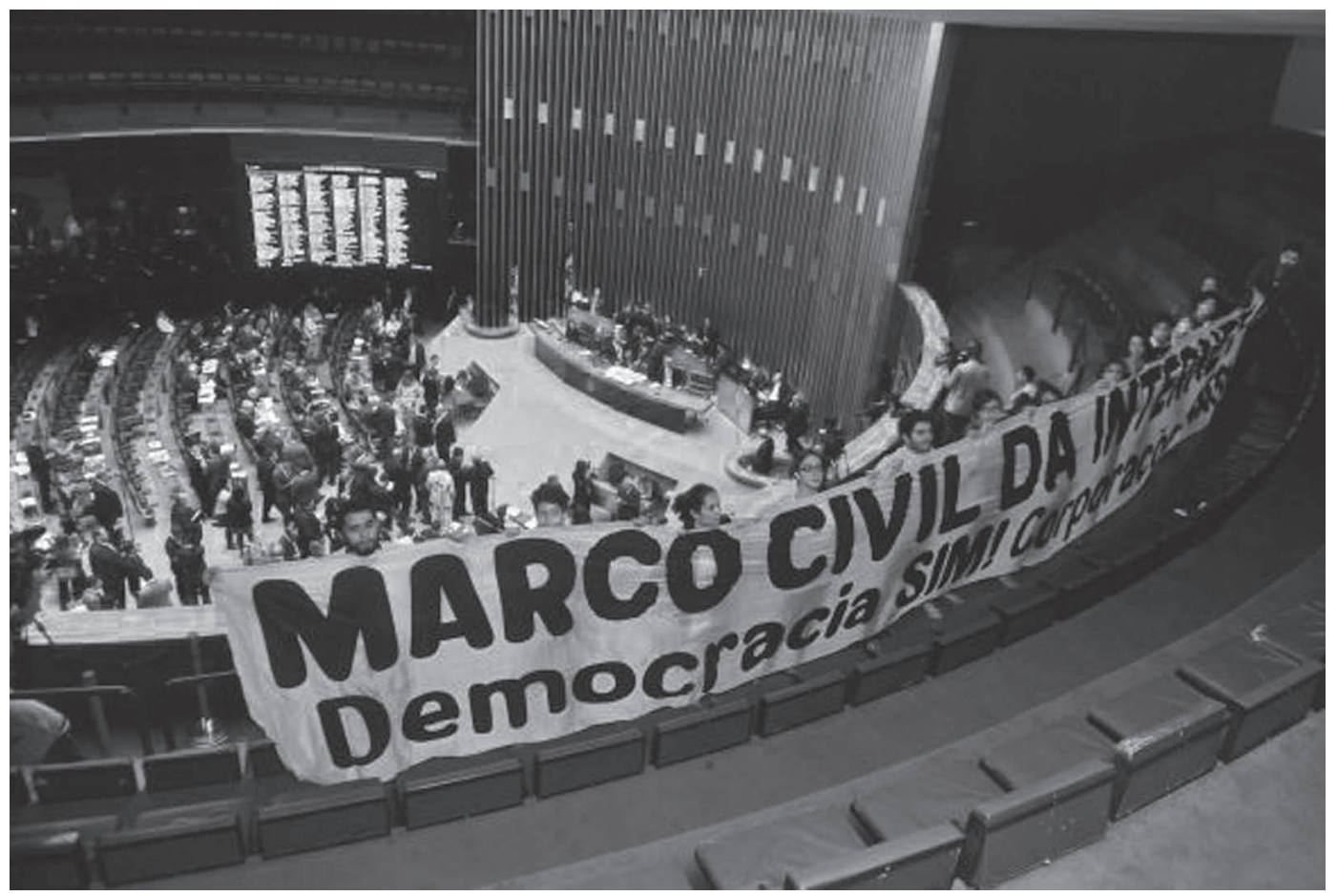

1. Votação do Marco Civil da internet, abril de 2014. Foto Marco

Civil Gustavo Lima/Câmara dos Deputados/Agência Brasil.

Mas o controle não se restringe ao país e alcança dimensão internacional pela ação de empresas sediadas nos Estados Unidos. Foi o que ocorreu com o WikiLeaks, organização de mídia sem fins lucrativos, que vem se tornando famosa pela divulgação de dados e informações de governos e empresas considerados relevantes para a sociedade, que teve os pagamentos de contribuições bloqueados, mesmo estando sediado na Suécia (ASSANGE, 2015).

\section{O Marco Civil da Internet e as possibilidades de expansão do ativismo virtual}

Conforme a Pesquisa Nacional por Amostra de Domicílio - PNAD 3 , em 2011 cerca de $36,5 \%$ das residências do Brasil possuíam microcomputador com acesso à internet, sendo que o percentual de pessoas de 10 anos ou mais de idade que acessaram a internet passou de 20,9\% (31,9 milhões) em 2005 para 46,5\% (77,7 milhões) em $2011^{4}$.

No segundo trimestre de 2013 foram mais de 105 milhões de usuários na internet, com acessos em domicílios, trabalho, lan houses, escolas, locais públicos e outras localidades ${ }^{5}$. Dados de 2012 apontam o país como o $5^{\circ}$ país mais conectado do mundo ${ }^{6}$. Diversos podem ser os usos da internet, desde comércio eletrônico, bate-papo, estudos e pesquisas, ciberativismo, mas o que se evidencia é a grande expansão do uso da rede que vem se tornando um hábito no país. No mesmo período tramitou no Congresso Nacional o Projeto de Lei no 2.126/11, visando instituir princípios, garantias, direitos e deveres para usuários, provedores de serviço e de conteúdo e demais agentes envol- 
vidos com o uso da internet ${ }^{7}$, posteriormente aprovado e transformado na Lei de $\mathrm{n}^{\mathrm{o}}$ 12.965, de 23 de abril de 2014, conhecida como o Marco Civil da Internet no Brasil.

Sua tramitação no legislativo nacional foi precedida de amplo debate público conduzido pelo Ministério da Justiça, tendo recebido mais de 2.000 contribuições. É considerado a "constituição da internet".

Composta de 5 capítulos e 32 artigos, a Lei destaca nos seus princípios o exercício da cidadania em meios digitais, a garantia da liberdade de expressão, comunicação e manifestação de pensamento, a proteção da privacidade e dos dados pessoais dos usuários, a preservação e garantia da neutralidade ${ }^{10}$ da rede.

Pela Lei, são invioláveis a intimidade da vida privada e o fluxo de comunicações. Somente podem ser divulgados por ordem judicial, sendo vedado bloquear, monitorar, filtrar ou analisar o conteúdo dos pacotes de dados.

Qualquer operação de coleta, armazenamento, guarda e tratamento de registros, dados pessoais ou de comunicações por provedores de conexão e de aplicações de internet em que pelo menos um desses atos ocorra no país, deverão ser obrigatoriamente respeitar a legislação brasileira e os direitos à privacidade, à proteção dos dados pessoais e ao sigilo das comunicações privadas e dos registros desde que pelo menos um dos terminais esteja localizado no Brasil ou que oferte serviço ao público brasileiro ou pelo menos uma integrante do mesmo grupo econômico possua estabelecimento no Brasil, mesmo que as atividades sejam realizadas por pessoa jurídica sediada no exterior.

O Deputado Federal Alessandro Molon ${ }^{11}$, relator do Projeto de Lei do Marco Civil da Internet e importante interlocutor de movimentos sociais para garantir o uso da rede para o fortalecimento de práticas democráticas, entende que o Marco Civil pode ser considerado uma referência para o debate sobre a participação da sociedade civil na luta pelos ideais, direitos e desejos cidadãos para que não prevaleça uma lógica de mercado na definição de políticas públicas. Trata-se de uma saída pela participação democrática, que possibilita contrabalançar o peso do mercado nessas decisões que o Estado brasileiro vai tomando. Segundo o deputado, na própria aprovação do Marco Civil a participação da sociedade civil foi decisiva. Ela cobrou antes, durante e depois uma legislação para a internet que atendesse aos seus desejos que confrontavam com outro Projeto de Lei que foi denominado de o AI-5 digital pelas restrições de direitos e vigilância que impunha ao uso da rede.

Pela neutralidade da rede, um dos pilares do Marco Civil da Internet, é possível acessar conteúdos sem as restrições impostas pelo direcionamento de conteúdos conforme os interesses do mercado. Ou seja, sem a neutralidade da rede torna-se mais acessável um grande site de notícias do que um blog alternativo. A neutralidade impede isso, pois coloca todos no mesmo patamar, condição essencial para que esse tipo de informação chegue à sociedade e possibilite o debate acerca de diferentes posicionamentos.

O Marco Civil da Internet tem atuado em três frentes: a) Liberdade de expressão, b) Garantia da privacidade e c) Neutralidade da rede, mas ainda não há uma arquitetura institucional, tipo criação de órgãos, articulação com demais poderes etc., para que o governo possa atuar para garantir na prática cada uma dessas frentes. Inicialmente, a fiscalização será de responsabilidade dos órgãos ligados à proteção do consumidor, ao Ministério da Justiça, à Anatel, mas a internet coloca desafios que apontam para a necessidade de outras agências e órgãos como por exemplo uma agência reguladora 


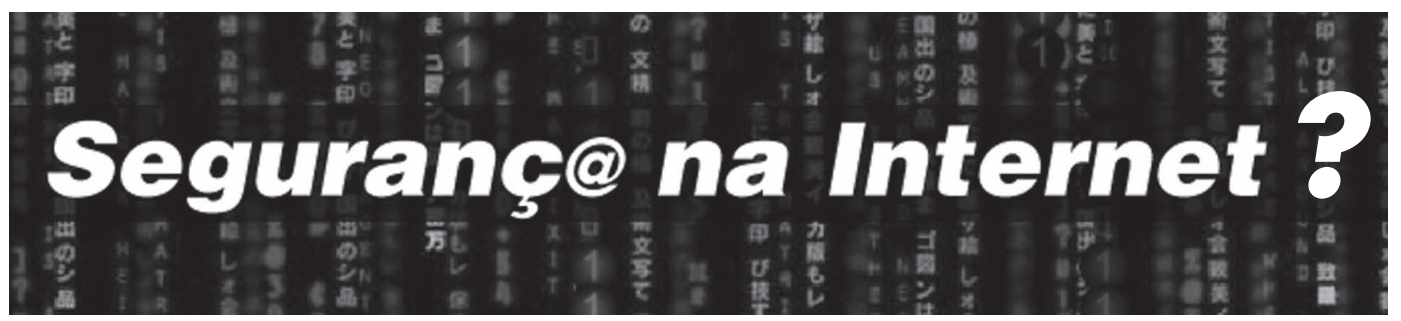

que fiscalize a própria internet, o cumprimento da lei na internet e que talvez venha a ser em algum futuro próximo um desenvolvimento do CGI - Comitê Gestor de Internet brasileira responsável pela governança da internet no Brasil.

Para o Deputado, o futuro da democracia passa pela internet. E o futuro da internet passa pela neutralidade da rede. A internet, na sua visão, pode ser considerada uma nova Ágora, um novo lugar onde a política, o debate político acontece com características especiais, mas isso não dispersa, não elimina o corpo-a-corpo. Porém é, sem dúvida, uma ferramenta poderosa. $\mathrm{E}$ do mesmo modo que a democracia fortaleceu a internet com a aprovação do Marco Civil, cabe agora usar internet para fortalecer a democracia. Movimentos contestatórios como o Occupy Wall Street, Indignados da Espanha e a Primavera Árabe utilizaram a internet como meio de mobilização, o que demonstra sua importância no fortalecimento da democracia, não substituindo a praça pública por uma praça virtual, mas reaproximando representantes de representados, permitindo o convívio entre democracia representativa e democracia participativa. Fazer esse equilíbrio é um grande desafio.

\section{Considerações finais}

Apesar da sedução que a internet proporciona, pela facilidade de comunicação, acesso à informação e potencial de interação, seu uso é também um modo de veicular uma ideologia, universalizar padrões culturais e controlar as pessoas e a participação política. E isso não pode ser negligenciado. Pelo contrário, o uso da internet deve ser objeto de debate e proposição de ações que valorizem e preservem o potencial da rede. Sua disseminação não deve representar uma renúncia e capitulação de outros modos de vida nem ser instrumento de vigilância. O Marco civil da Internet pode ser esse caminho (embora não único), por meio de seus pilares de liberdade de expressão, garantia da privacidade e a neutralidade da rede. Mas a disputa está aberta. Os próximos passos da regulamentação serão decisivos dessa garantia.

O espaço da internet, com seus aplicativos e recursos de produção acessíveis, pode ser um campo estratégico de contra-hegemonia para os movimentos sociais. Disputar esse espaço com o monopólio da informação exercido pelas empresas de comunicação é uma parte da luta política. Tais empresas cumprem relevante papel na hegemonia da classe dominante, oferecendo "mais do mesmo" em termos de conteúdos e imagens conforme seus interesses políticos e comerciais.

Mas isso é parte da disputa. É necessário ir além da produção e disseminação de informações contra-hegemônicas e dos limites impostos pela ideia de participação democrática. 
Utilizar as TIC como ferramenta de participação e mobilização pode ser um caminho útil na identificação de problemas e de luta política para a construção de uma nova sociabilidade. Experiências que podem ser consideradas exitosas têm sido tentadas nos movimentos sociais. Os resultados positivos na mobilização popular para causas políticas, ambientais, sociais e de cidadania estimulam a se perseguir num processo de democratização da rede de modo a se ampliar e intensificar o seu uso, revertendo práticas e construindo novos olhares acerca da realidade.

Afinal, do mesmo modo que a tecnologia não é neutra e cumpre um papel político dentro de uma hegemonia, sua utilização, com outros propósitos, pode representar uma importante ação de contra-hegemonia. No entanto, concebê-la como uma nova Ágora não pode significar transferir a luta política para o ambiente virtual limitando a ação na realidade concreta. Afinal, é no mundo concreto das contradições que a Ágora da internet começa a ser construída.

\section{Referências bibliográficas}

ASSANGE, Julian et al. Cypherpunks: liberdade e o futuro da Internet. São Paulo: Boitempo, 2013.

ASSANGE, Julian. Quando o Google encontrou o WikiLeaks. São Paulo: Boitempo, 2015.

CASTELLS, Manuel. A Sociedade em rede. São Paulo - a era da informação: economia, sociedade e cultura vol. I: São Paulo: Paz e Terra, 3a edição, 2000.

. A Galáxia Internet: reflexões sobre Internet, negócios e sociedade. Lisboa: Fundação Calouste Gulbenkian, 2004

. O poder da identidade - a era da informação: economia, sociedade e cultura vol. II. São Paulo: Paz e Terra, 6a edição, 2008.

. Redes de indignação e esperança: movimentos sociais na era da Internet. Rio de Janeiro: Zahar, 2013.

DAGNINO, Renato. Enfoques sobre a relação Ciência, Tecnologia e Sociedade: Neutralidade e Determinismo. Disponível em http://www.oei.es/salactsi/rdagnino3. htm, acessado em 24/09/2012.

DAGNINO, Renato e NOVAES, Henrique. O fetiche da tecnologia. Revista Organizações \& Democracia. Marília-SP, Ed Unesp, n⿳0 5, 2004.

FEENBERG, Andrew. Teoria Crítica da Tecnologia. Disponível em http://www. sfu.ca/ andrewf/critport.pdf, acessado em 31/01/2011.

MARCUSE, Herbert. Tecnologia, guerra e fascismo - coletânea de artigos. São Paulo: Unesp, 1999.

MARX, Karl. O capital - Crítica da Economia Política. Livro primeiro - o processo de produção do Capital. Volume I 2a Edição. Rio de Janeiro: Civilização Brasileira, 1971.

Moraes, Denis de. O concreto e o virtual: mídia, cultura e tecnologia. Rio de Janeiro: DP\&A, 2001.

NEDER, Ricardo (org.). Andrew Feenberg: racionalização democrática, poder e tecnologia. Brasília: Observatório do Movimento pela Tecnologia Social na América Latina/Centro de Desenvolvimento Sustentável - CDS. Ciclo de Conferências Andrew Feenberg. - série Cadernos PRIMEIRA VERSÃO: CCTS - Construção Crítica da Tecnologia E Sustentabilidade. Vol. 1. Número 3. 2010. 
Rüdiger, Francisco. Elementos para a crítica da Cibercultura: sujeito, objeto e interação na era das novas tecnologias de comunicação. São Paulo: Hacker Editores, 2002.

\section{Notas}

1 Conforme http://www.cartacapital.com.br/tecnologia/twitter-a-nova-via-da-revolucao, acessado em 04/05/2012.

2 Conforme http://noticias.uol.com.br/internacional/ultimas-noticias/the-new-york-times/2014/12/16/opiniao-negocio-do-google-e-facebook-e-a-destruicao-industrial-da-privacidade.htm, acessado em 09/01/2015.

3 Conforme http:/www.ibge.gov.br/home/presidencia/noticias/imprensa/ppts/ 00000012962305122013234016242127.pdf

4 Não estão incluídos acessos à internet por telefone celular nem em locais públicos.

5 http://info.abril.com.br/noticias/tecnologia-pessoal/2013/10/ibope-aponta-que-acesso-a-internet-cresce-3-no-2-trimestre.shtml, acessado em 14/04/2015.

6 Conforme http://info.abril.com.br/noticias/internet/brasil-e-o-quinto-pais-mais-conectado-do-mundo-22042012-7.sh1?utm_ source=feedburner\&utm_medium $=$ feed\&utm_campaign $=$ Feed\%3A+NoticiasINFO-Internet+(Not\%C3\%ADcias+INFO+-+Internet), acessado em 14/04/2015.

7 Conforme http://www2.camara.leg.br/documentos-e-pesquisa/fiquePorDentro/ temas/marco-civil, acessado em 08/08/2014.

8 Conforme http://www.planalto.gov.br/ccivil_03/_ato2011-2014/2014/lei/112965. htm, acessado em 05/08/2014.

9 Conforme http://www.justica.gov.br/noticias/marco-civil-da-internet-pode-ser-votado-nesta-terca-11-na-camara-dos-deputados, acessado em 08/09/2014.

10 Entende-se por neutralidade da rede a garantia de que não há privilégio no tráfego de conteúdo pela Internet. $\mathrm{O}$ acesso deve ser igual para todos os tipos de informações que circulam.

11 As informações sobre o posicionamento do Deputado Molon com relação ao Marco Civil da Internet foram obtidas em uma entrevista gravada em 28 de julho de 2014. 